\title{
The Research on Personnel Training of Information Management and Information System under the Background of Big Data
}

\author{
Chunyan Zhao \\ Economic Management Department \\ Changchun University of Technology \\ Changchun, China \\ 1079077872@qq.com
}

\begin{abstract}
The development of large data and its technology has made the demand for large data talents increased rapidly in society. However, the knowledge structure of information management talents trained in Colleges and universities could not fully meet the needs of the development of the big data industry. The information management and information system major, as the training of talents in the field of information management, should catch the chance; review its own problems, Adjust in time to meet challenges. On the basis of clarifying the demand of big data on talent ability and combining with the actual situation of Colleges and universities, this paper finds out the problems in talent training and puts forward corresponding counterme asures and Suggestions.
\end{abstract}

Keywords-Big data; Information management and information system; personnel training; curriculum

\section{WHY PUT FORWARD THE QUESTION}

The term "big data" first appeared in 1980 in the book "the third wave" by Futurist Toffler. But it didn't get much attention at the time. With the rapid development of computer, communication technology and Internet, a large amount of data has been accumulated on the network, forming a valuable data "mine". Some people with creative thinking have extracted valuable information from these data "mineral deposits". They have made right decisions with the help of information and provided high-quality services. Since 2009, "big data" has become a popular word in the Internet technology industry. And the report on "big data" issued by the McKinsey Co in June 2011 was first highly valued by the financial community and gradually received the attention from all walks of life. Now, big data has appeared in all kinds of media with smothering force. Big data technology has achieved remarkable results in innovative applications in the fields of Commerce, finance, transportation, education, medical treatment, government administration and public service. It might even be called a miracle. The applications of big data have penetrated into all aspects of our life. Faced with the huge potential value of big data, it is urgent for people who are proficient in big data technology to create new applications and explore new values. In large data technology, there have been major changes in the ways and means of obtaining, preserving, processing, analyzing, and providing data. The application of large data depends on many new technologies such as data mining, cloud computing, intelligent terminal equipment, the Internet of things and so on. This requires that the personnel engaged in large data technology work have corresponding knowledge. As the main practitioner in the field of data processing, there is a certain gap between the knowledge structure of information management and information system (here in after referred to as information management) students trained in colleges and universities and the technology required by large data at present. How to cultivate information management and information system professionals who meet the requirements of big data has become a problem that colleges and universities must face.

\section{THE ABILITY REQUIREMENTS OF BIG DATA TO PERSON}

Excellent big data people often make amazing achievements with big data. In 2013, David Rothschild, an economist at the Microsoft Research Institute in New York, accurately predicted 19 of the 24 Oscar awards with the big data. It has become a hot topic of people's attention. Moreover, David Rothschild continued to research, and in the following year, he successfully predicted 21 of the 24 awards of the eighty-sixth Oscar awards. This is enough to show people the magic power of big data technology and the ability of excellent big data talents. [1] So what are the necessary abilities for an excellent big data person? The field of big data can be subdivided into three directions: big data technology, big data engineering, and big data science. Big data technology focuses on how to quickly access valuable information in a vast and diverse data ocean. Big data engineering pays more attention to a series of system behaviors of planning, construction, operation and management of major data. However, big data science focuses more on discovering the laws found in big data and exploring their value and influence on natural activities and social life. ${ }^{[2]}$ Data warehouse and data mining technology, data security technology, data analysis technology, model prediction technology are the core technologies in the field of big data. Big data technical personnel should have the following abilities:

First of all, the big data engineering technical ability should be had. The ability of engineering technology includes the ability to build data platform and the operation and maintenance of data platform and data acquisition, cleaning, storage, organization, transmission and so on. Also should have 
the ability to program, can skilled use of Map Reduce, Hadoop and other technical tools, master data filtering technology, and have data filtering capabilities. In the case of big data acquisition, the acquisition of big data cannot rely solely on the manual input of various kinds of data in traditional daily work. More data acquisition depends on various automatic data acquisition technologies, such as automatic acquisition by sensors, automatic acquisition by software tracking the behavior of people's operations, and "crawling" of various unit data resources. This requires big data personnel to understand various terminal sensor pieces, understand the tracking technology of network operation behavior, and have the ability to use crawler software. ${ }^{[3]}$

Secondly, the ability of big data processing and analysis should be had. In order to provide assistance for high-level decision-making,big data analysts should effectively predict relevant trends by data mining, analysis and mining it's results. Data mining requires constructing data models and describing mining algorithms. This requires practitioners to have the ability to construct data models and write excellent algorithms. It requires big data analysts to master data analysis languages such as R and Python, and can use tools to do data mining and analysis. Knowledge of management, economics, behavioral science, statistics, social sciences and other disciplines should also be provided. They can effectively analyze big data and interpret the analysis results. At the same time, they also need to have good communication skills, insight and vision to be able to discover value from a large amount of noisy data.

Thirdly, better learning ability should be had. The knowledge system in the field of big data is complex, and it's related technology is developing rapidly. It is necessary for practitioners to keep learning to keep up with the speed of knowledge refurbishment. In order to discover the value of large data creatively, it is also necessary to integrate knowledge and apply it comprehensively. ALL these require practitioners to have good learning ability.

\section{THE EXISTING PROBLEMS OF INFORMATION MANAGEMENT MAJOR IN COLLEGES AND UNIVERSITIES IN THE CULTIVATION OF BIG DATA TALENTS}

\section{A. The existing curriculum cannot cover the requirements of big data technology}

From the perspective of curriculum setting, the current curriculum provision in many universities, especially the compulsory courses, is based on the ability to develop information systems. There are a small number of subjects related to big data technology in elective courses. However, there is no corresponding curriculum for cloud computing, Internet of things technology, data analysis language technology, tool technology, data science, etc. required by big data.

\section{B. Limited by school hours, the content of some courses are not in-depth}

Since information management specialty itself is a multidisciplinary and interdisciplinary comprehensive discipline involving management science, IT science, economics and other disciplines, this leads to the need to set up multiple courses in this discipline. However, due to the restriction of the total class hours, many courses' class hours are not enough, and only the basic contents can be taught. For example, in some computer language courses, only basic operations can be taught, and the depth is not enough, which leads to the lack of students' actual working ability.

\section{The teacher's knowledge of big data is weak}

Big data has emerged in China only in recent years. There is no special big data major in China. Teachers of information management major in colleges and universities are all from management science, engineering and computer science, and have no working experience in big data. Teachers' own knowledge of big data is weak. Moreover, there are very few talented people who really have big data technology, so it is difficult to find external teachers. Even if they can be hired, the time for real teaching could not be guaranteed.

\section{Insufficient teaching resources}

On the one hand, there is no mature textbook that can integrate big data knowledge system. On the other hand, information management is a highly practical discipline. Many computer courses require students to do things themselves to really understand and master them. In class, if students can directly verify the content that teacher taught, it will greatly improve their understanding, creativity and concentration, and achieve a good teaching results. This requires advanced teaching equipment and teaching environment to ensure that students can participate in real time during class. Moreover, such courses also need to strengthen the digestion and understanding of contents through experiments and curriculum design. This requires that the major should have an advanced and complete experimental environment. However, due to funding constraints, many university classrooms are only ordinary multimedia classrooms. Students cannot operate directly in class. There are also cases that the laboratories' equipment and software deployment are backward. The software that teachers use in class is also the free trial software or pirated software that they find through various channels. Such software itself is not fully functional. It is also difficult to configure the real environment in which applications can be developed and run using such software. All these will affect the cultivation of students' application ability.

\section{COUNTERMEASURES AND RECOMMENDATIONS}

In order to meet the demand of the development of big data technology to the ability of information management professionals, combining with the actual situation of Chinese universities, combined with the actual situation of universities in China, we can start from the following aspects and actively respond.

\section{A. Adjust the curriculum at the right time}

At present, China's first National Standards for the teaching quality of undergraduate majors in Colleges and Universities has been promulgated. We should make full use of the expand space that reserved in addition to the unified requirements course which information management major put forward in "standards" to adjust the curriculum. On the one hand, we should appropriately increase the course of large data technology, such as 
increasing the Python language of large data processing. on the other hand, we should adjust the content of the existing courses, expand the depth and breadth of the course content, such as adding data warehouse and business intelligence in the course of database design and management, integrate the introduction of the Internet of things, intelligent terminals and other equipment technology into the course of computer basic, integrate the content of large data applications into the course of management information system, information system case analysis. In this way, we can cultivate students' big data literacy without increasing the number of courses.

\section{B. Make full use of external teaching resources}

With the gradual deepening of the application of Internet technology in education, the current teaching resources on the Internet are more and more abundant. The development of MOOCs, micro class and mobile App teaching software ${ }^{[4]}$ is in the ascendant. There are many kinds of teaching video software, a lot of professional knowledge in micro-blog, QQ space and so on, and many new technical courses are also set up in various social training institutions. Students should be encouraged to make full use of various off-campus teaching resources and study independently to make up for the shortage of on-campus teaching. Many colleges and universities have established a cooperative relationship with some training institutions. Their Application environment is well equipped and their courses content is practical and advanced. Using the internship and practice links, they have obtained some free training opportunities for students, and made up for some deficiencies in teaching contents and experimental environment.

\section{Establish internship bases}

In order to cultivate students' practical ability and enhance their professional literacy, it is necessary to establish internship practice platform to meet the professional needs. On the one hand, we must strengthen the construction of laboratory on campus and invest money to purchase advanced equipment and software. On the other hand, we should make full use of social resources, strengthen the cooperation between schools and enterprises, and establish contact with software development companies and large data enterprises so that students can contact and participate in practical applications in professional fields by internships and practical training and other practical links. It is also possible to use the form of "credit replacement" to allow students to study directly in the enterprise and receive targeted training from the enterprise. This can not only make up for the problem that the content of teaching in the school is out of line with the actual application of the enterprise, but also can open up a way for students to find employment.

\section{Strengthen teachers training}

The development of the knowledge field of information management disciplines is very rapid. Even some of the knowledge learned in the school may have fallen behind before leaving the school. This requires that the teachers of this major must continue to learn to keep up with the pace of knowledge updating and development. However, teachers themselves must complete heavy teaching and scientific research tasks, and some of the software and hardware content of computers need relevant environmental support when learning. In particular, some software prices are very high and teachers could not afford the costs. Therefore, it is not realistic to rely entirely on teachers 'self-study. This requires the school to invest funds and manpower, so that teachers have the opportunity to learn in leading enterprises and institutions in the industry and continuously improve their own knowledge structure. In this way, they can cultivate applied talents with advanced knowledge and meet social needs.

\section{CONCLUSION}

The rise and application of big data has put forward new requirements for professional personnel training in information management and information systems. Colleges and universities should face up to their own problems, make timely adjustments, improve them from the aspects of curriculum, teaching resources, teaching environment, teachers, cooperation between school and enterprise and so on. Keep pace with the times to train information management professionals to meet the needs of the development of China's big data era.

\section{REFERENCES}

[1] You on the road. Ten interesting "big data" classic data mining cases. zhihu. https://zhuanlan.zhihu.com/p/26787943

[2] Wu Qing, Li Jing, "Analysis of the impact of the construction of information system and information management specialty in the era of “ 'big data' ” [J]. Computer knowledge and technology, Vol. 11, No. 28(2015.10)

[3] Lü Chenggong, Wei Yashuang, "Research on training mode of big data analysis talents in information management and Information System Specialty" [J]. Computer knowledge and technology, Vol.14,No.3(2018.1)

[4] Zhou Yaolin, Huang Chuanchuan, "Research on the reform of information management talents train ing mode in the era of big data" [J]. Chinese Higher Education Research. 2017(10) 